\title{
Histological grading in lung cancer: one system for all or separate systems for each histological type?
}

\author{
William D. Travis ${ }^{1}$, Elisabeth Brambilla ${ }^{2}$ and Kim R. Geisinger ${ }^{3}$
}

Affiliations: ${ }^{1}$ Dept of Pathology, Memorial Sloan Kettering Cancer Center, New York, NY, USA. ${ }^{2}$ Dept d'Anatomie et Cytologie Pathologiques, CHU Albert Michallon, University Joseph Fourier, INSERM U823 Institut Albert Bonniot, Grenoble, France. ${ }^{3}$ Dept of Pathology, University of Mississippi Medical Center, Jackson, MS, USA.

Correspondence: William D. Travis, Dept of Pathology, Memorial Sloan Kettering Cancer Center, 1275 York Ave, New York, NY 10065, USA. E-mail: traviswamskcc.org

0 @ERSpublications

Two recent studies show the importance of tumour budding and nest size in grading of lung squamous cell carcinoma http://ow.ly/WTaQ2

The grading of cancer is a histological method intended to help predict prognosis based on specific morphological features. It typically is based on architectural or cytological features (nuclear grade or number of mitoses), or in some cases, a combination of both. Grading is usually broken down into a spectrum from well differentiated (grade 1) to the most poorly differentiated (grade 3 or 4 ). The number of grades ranges from two to five [1-3]. The highest grade tumours (grade 3 or 4) lack any specific differentiation. The morphological criteria for grading usually differ from that used in histological classification, but in some systems, histological classification is a major component of grade.

Clinically relevant and reproducible histological grading systems have been well established for many years in cancers of the breast [4-6], prostate [1-3], endometrium [7, 8], soft tissue sarcomas [9] and kidney [10-12]. However, for lung cancer, a widely accepted histological grading system with clearly defined criteria and demonstrable clinical significance has not yet been developed, and there is a great need for this $[13,14]$.

In lung cancer, certain tumours are known to be high grade including small cell lung carcinoma (SCLC), large cell carcinoma, pleomorphic carcinoma, carcinosarcoma and pulmonary blastoma [13]. In addition, for lung neuroendocrine tumours, the histological subtyping is primarily based upon mitotic count and necrosis correlating with the low-grade typical carcinoid, intermediate-grade atypical carcinoid, and high-grade SCLC and large cell neuroendocrine carcinoma, where the latter two are distinguished primarily by cytological characteristics [13].

For lung adenocarcinoma, recent advances show emerging data that are likely to result in a grading system in the near future. This may best include a combination of architectural patterns or histological subtyping and nuclear features such as mitotic counts. Based on the 2011 International Association for the Study of Lung Cancer/American Thoracic Society/European Respiratory Society classification of adenocarcinoma, five different histological subtypes were proposed [15] and based on the predominant subtype, significant prognostic differences have been demonstrated [16-22]. This provides a simple architectural grading system, most applicable to resection specimens, with grade 1 (well differentiated; lepidic predominant), grade 2 (moderately differentiated; acinar or papillary predominant) and grade 3 (poorly differentiated; solid or micropapillary predominant). Other proposed grading schemes include the two most predominant patterns, the highest grade pattern, or nuclear features such as size or mitotic count in combination with an architectural approach like the predominant subtype. In a study of stage I adenocarcinomas, SicA et al. [23]

Received: Jan 062016 | Accepted: Jan 072016

Conflict of interest: None declared.

Copyright (CERS 2016 
proposed a grading system using a score created by summing the two most predominant grades and stratified tumours into a three-tiered classification, which also correlated well with prognosis. By using the predominant type to grade adenocarcinoma, it appears that the acinar pattern is the most common and the most heterogeneous. Several studies have suggested the acinar subtype can be divided further into prognostically significant subsets. Two studies, by KADOTA et al. [24] and VON DER THusen et al. [25], found the combination of predominant histological pattern and mitotic activity was helpful in separating the intermediate group into well and poorly differentiated tumours. In addition, the cribriform pattern has been identified to be a poor-prognostic subset of the acinar subtype, similar to the solid type [26-28]. NAKAZATO et al. [29] found that nuclear size was a valuable predictor of prognosis. However, this has not been confirmed by other investigators [24, 25].

Grading has implications beyond just predicting prognosis. Recent data suggest that the poorly differentiated solid and micropapillary histological subtypes not only correlate with poor survival but are also predictive of survival benefit with cisplatin-based adjuvant chemotherapy in patients with surgically resected adenocarcinomas [30].

Since a definitive grading system has not been established for resected lung adenocarcinomas and no grading system is recognised in non-resection specimens, there are limited data on the prognostic significance of histological features in this setting. However, a recent study in patients with advanced disease evaluated predominant subtype in core biopsies and classified tumours with papillary-, micropapillary- and solid-predominant patterns to be high grade. Patients with these high-grade patterns had better response rates to platinum-based therapy and progression-free survival than patients with lower grade adenocarcinomas $[31,32]$. Further validation is needed to demonstrate clinical relevance for grading in non-resection specimens.

In this issue of European Respiratory Journal, WeICHERT et al. [33] have proposed a grading system for squamous cell carcinoma of the lung. It is based upon a scoring system by summing the scores for two independent prognostic markers including tumour budding and tumour cell nest size (table 1). This scoring system is based on a detailed clinical and pathological assessment of a large retrospective series of surgically resected lung squamous cell carcinomas and it demonstrates prognostic significance for overall survival by univariate and multivariate analysis.

Importantly, this study provides validation of the work by KADOTA et al. [34], who also found tumour budding and single cell invasion were independent prognostic factors for overall survival. The method of analysis for tumour nest size and tumour budding was slightly different in the two studies. According to KADOTA et al. [34], survival according to single cell invasion was significant and an independent prognostic factor, while in the WEICHERT et al. [33] study, poor prognosis was correlated with small (fewer than five cells) to intermediate (five to 15 cells) versus large nest size ( $>15$ cells) rather than just single cell invasion. Also, the stratification of budding was significant in the KADOTA et al. [34] study with a cut off of 10 buds per high-power field (HPF), while in the WEICHERT et al. [33] study, budding was stratified according to no budding, $<15$ budding foci per $10 \mathrm{HPFs}$ and $\geqslant 15$ foci per $10 \mathrm{HPFs}$. Future studies should further investigate the optimal stratification for tumour budding and tumour cell nest size according to both approaches. Interestingly, in contrast to lung adenocarcinoma, there is no consistent prognostic significance to the three main histological subtypes of

\begin{tabular}{|c|c|c|}
\hline Morphologic feature & Score & Definition \\
\hline Tumour budding & $\begin{array}{l}1 \\
2 \\
3\end{array}$ & $\begin{array}{l}\text { No budding in } 10 \mathrm{HPFs} \\
<15 \text { budding foci per } 10 \mathrm{HPFs} \\
\geqslant 15 \text { budding foci per } 10 \mathrm{HPFs}\end{array}$ \\
\hline Tumour nest size & $\begin{array}{l}1 \\
2 \\
3 \\
4\end{array}$ & $\begin{array}{l}>15 \text { cells (large nest size) } \\
5-15 \text { cells (intermediate nest size) } \\
<5 \text { (or } 2-4 \text { ) cells (small nest size) } \\
\quad \text { Single cell invasion }\end{array}$ \\
\hline Combined score & $\begin{array}{c}2-3 \\
4-6 \\
7\end{array}$ & $\begin{array}{l}\text { Grade } 1 \text { (well differentiated) } \\
\text { Grade } 2 \text { (moderately differentiated) } \\
\text { Grade } 3 \text { (poorly differentiated) }\end{array}$ \\
\hline
\end{tabular}

HPF: high-power field. Reproduced and modified from [33]. 
squamous cell carcinoma: keratinising, nonkeratinising and basaloid. WEICHERT et al. [33] found a worse prognosis was associated with the keratinising subtype but КАDОTA et al. [34] did not find any significant association between subtype and patient outcome. It is intriguing that, although others have reported poor survival for basaloid carcinomas [35], both of these studies were unable to demonstrate poor survival for the basaloid tumours [33, 34]. In the study by КАDOTA et al. [34], basaloid tumours showed a trend for better overall survival ( $69 \%$ versus $58 \%, \mathrm{p}=0.071)$. The study by WeICHERT et al. [33] showed significantly better overall survival for nonkeratinising and basaloid $(71.5 \%$ and $68.8 \%$, respectively) tumours compared to keratinising (62.1\%) tumours ( $\mathrm{p}=0.037)$. Compared to the Moro-SiвILOT et al. [35] study, which included 90 cases of basaloid carcinoma, the KADOTA et al. [34] study only had 33 cases and the WEICHERT et al. [33] study only had 18 cases, so further investigation is needed to address the clinical behaviour of this tumour. It is peculiar in the WEICHERT et al. [33] dataset why patients with keratinising tumours would have a worse outcome than the nonkeratinising or basaloid tumours because keratinising tumours are typically regarded as better differentiated. Also, in both studies, no prognostic significance was reported according to proliferation rate by Ki-67 staining $[33,34]$. It is of interest that in both studies, survival analysis using overall survival rather than disease free survival or cumulative incidence of recurrence appeared to provide the most robust prognostic correlations.

Despite the similarity in results between the WEICHERT et al. [33] and KADOTA et al. [34] studies, there are some differences. Nuclear diameter was prognostically significant in the study by KADOTA et al. [34] but it had no impact on survival in the study by WeICHERT et al. [33]. In addition, WEICHERT et al. [33] found increased stromal content correlated with worse outcome but KADOTA et al. [34] did not. Although KADOTA et al. [34] did not find prognostic significance according to nuclear atypia, chromatin pattern, presence of nucleoli or mitotic rate, these features were not reported by WeICHERT et al. [33].

In summary, both the WEICHERT et al. [33] and KADOTA et al. [34] investigations demonstrate that unlike lung adenocarcinoma, the histological grading system for lung squamous cell carcinoma should not include histological subtyping or nuclear features such as mitotic rate, but rather the features of tumour budding and tumour nest size. Applying this system will be challenging for practicing pathologists who may have never given attention to the histological features of tumour nest size and budding. An inherent challenge in analysing these features is selecting the field with maximum tumour budding, and assessing tumour nest size both in the entire tumour and at the tumour edge. However, since two large studies have now demonstrated the prognostic importance of these features in squamous cell carcinoma, they may be the most important histological factors in predicting prognosis in this tumour and warrant further investigation. Another implication of these two studies is that they clearly show that the components of the grading system for squamous cell carcinoma must be different from that for other major lung cancers including adenocarcinomas and neuroendocrine tumours.

There is a great need for further study of histological grading in lung cancers, particularly lung adenocarcinoma and squamous cell carcinoma. Hopefully, over the coming decade, before the next World Health Organization classification revision, validated and reproducible systems will be established. Since writing this editorial, we have become aware of another similar study of resected lung squamous cell carcinomas where it was shown that tumour budding, single cell invasion, mitoses, and higher cytologic atypia were independent predictors of worse overall survival [36].

\section{References}

1 Carter HB, Partin AW, Walsh PC, et al. Gleason score 6 adenocarcinoma: should it be labeled as cancer? J Clin Oncol 2012; 30: 4294-4296.

2 Amin MB, Lin DW, Gore JL, et al. The critical role of the pathologist in determining eligibility for active surveillance as a management option in patients with prostate cancer: consensus statement with recommendations supported by the College of American Pathologists, International Society of Urological Pathology, Association of Directors of Anatomic and Surgical Pathology, the New Zealand Society of Pathologists, and the Prostate Cancer Foundation. Arch Pathol Lab Med 2014; 138: 1387-1405.

3 Gleason DF. Histologic grading of prostate cancer: a perspective. Hum Pathol 1992; 23.

4 Bloom HJ, Richardson WW. Histological grading and prognosis in breast cancer; a study of 1409 cases of which 359 have been followed for 15 years. Br J Cancer 1957; 11: 359-377.

5 Rakha EA, Reis-Filho JS, Baehner F, et al. Breast cancer prognostic classification in the molecular era: the role of histological grade. Breast Cancer Res 2010; 12: 207.

6 Rakha EA, el-Sayed ME, Lee AH, et al. Prognostic significance of Nottingham histologic grade in invasive breast carcinoma. J Clin Oncol 2008; 26: 3153-3158.

7 Zaino RJ, Kurman RJ, Diana KL, et al. The utility of the revised International Federation of Gynecology and Obstetrics histologic grading of endometrial adenocarcinoma using a defined nuclear grading system. A Gynecologic Oncology Group study. Cancer 1995; 75: 81-86.

8 Zaino RJ. FIGO staging of endometrial adenocarcinoma: a critical review and proposal. Int J Gynecol Pathol 2009; 28: $1-9$. 
9 Guillou L, Coindre JM, Bonichon F, et al. Comparative study of the National Cancer Institute and French Federation of Cancer Centers Sarcoma Group grading systems in a population of 410 adult patients with soft tissue sarcoma. J Clin Oncol 1997; 15: 350-362.

10 Fuhrman SA, Lasky LC, Limas C. Prognostic significance of morphologic parameters in renal cell carcinoma. Am J Surg Pathol 1982; 6: 655-663.

11 Lee WK, Lee SE, Hong SK, et al. Characteristics and prognostic value of papillary histologic subtype in nonmetastatic renal cell carcinoma in Korea: a multicenter study. Urol J 2014; 11: 1884-1890.

12 Cornejo KM, Dong F, Zhou AG, et al. Papillary renal cell carcinoma: correlation of tumor grade and histologic characteristics with clinical outcome. Hum Pathol 2015; 46: 1411-1417.

13 Travis WD, Brambilla E, Burke AP, et al. WHO Classification of Tumours of the Lung, Pleura, Thymus and Heart. Lyon, International Agency for Research on Cancer, 2015.

14 Travis WD, Brambilla E, Nicholson AG, et al. The 2015 World Health Organization classification of lung tumors: impact of genetic, clinical and radiologic advances since the 2004 classification. J Thorac Oncol 2015; 10: $1243-1260$.

15 Travis WD, Brambilla E, Noguchi M, et al. The New IASLC/ATS/ERS international multidisciplinary lung adenocarcinoma classification. J Thorac Oncol 2011; 6: 244-285.

16 Yoshizawa A, Motoi N, Riely GJ, et al. Impact of proposed IASLC/ATS/ERS classification of lung adenocarcinoma: prognostic subgroups and implications for further revision of staging based on analysis of 514 stage I cases. Mod Pathol 2011; 24: 653-664.

17 Russell PA, Wainer Z, Wright GM, et al. Does lung adenocarcinoma subtype predict patient survival? A clinicopathologic study based on the new International Association for the Study of Lung Cancer/American Thoracic Society/European Respiratory Society international multidisciplinary lung adenocarcinoma classification. J Thorac Oncol 2011; 6: 1496-1504.

18 Warth A, Muley T, Meister M, et al. The novel histologic IASLC/ATS/ERS classification system of invasive pulmonary adenocarcinoma is a stage-independent predictor of survival. J Clin Oncol 2012; 30: 1438-1446.

19 Song Z, Zhu H, Guo Z, et al. Prognostic value of the IASLC/ATS/ERS classification in stage I lung adenocarcinoma patients-Based on a hospital study in China. Eur J Surg Oncol 2013; 39: 1262-1268.

20 Hung JJ, Yeh YC, Jeng WJ, et al. Predictive value of the International Association for the Study of Lung Cancer/ American Thoracic Society/European Respiratory Society classification of lung adenocarcinoma in tumor recurrence and patient survival. J Clin Oncol 2014; 32: 2357-2364.

21 Duhig EE, Dettrick A, Godbolt DB, et al. Mitosis trumps T stage and proposed International Association for the Study of Lung Cancer/American Thoracic Society/European Respiratory Society classification for prognostic value in resected stage 1 lung adenocarcinoma. J Thorac Oncol 2015; 10: 673-681.

22 Hung JJ, Yeh YC, Jeng WJ, et al. Prognostic factors of survival after recurrence in patients with resected lung adenocarcinoma. J Thorac Oncol 2015; 10: 1328-1336.

23 Sica G, Yoshizawa A, Sima CS, et al. A grading system of lung adenocarcinomas based on histologic pattern is predictive of disease recurrence in stage I tumors. Am J Surg Pathol 2010; 34: 1155-1162.

24 Kadota K, Suzuki K, Kachala SS, et al. A grading system combining architectural features and mitotic count predicts recurrence in stage I lung adenocarcinoma. Mod Pathol 2012; 25: 1117-1127.

25 von der Thusen JH, Tham YS, Pattenden H, et al. Prognostic significance of predominant histologic pattern and nuclear grade in resected adenocarcinoma of the lung: potential parameters for a grading system. J Thorac Oncol 2013; 8: 37-44

26 Kadota K, Yeh YC, Sima CS, et al. The cribriform pattern identifies a subset of acinar predominant tumors with poor prognosis in patients with stage I lung adenocarcinoma: a conceptual proposal to classify cribriform predominant tumors as a distinct histologic subtype. Mod Pathol 2014; 27: 690-700.

27 Moreira AL, Joubert P, Downey RJ, et al. Cribriform and fused glands are patterns of high-grade pulmonary adenocarcinoma. Hum Pathol 2014; 45: 213-220.

28 Warth A, Muley T, Kossakowski C, et al. Prognostic impact and clinicopathological correlations of the cribriform pattern in pulmonary adenocarcinoma. J Thorac Oncol 2015; 10: 638-644.

29 Nakazato Y, Maeshima AM, Ishikawa Y, et al. Interobserver agreement in the nuclear grading of primary pulmonary adenocarcinoma. J Thorac Oncol 2013; 8: 736-743.

30 Tsao MS, Marguet S, Le Teuff G, et al. Subtype classification of lung adenocarcinoma predicts benefit from adjuvant chemotherapy in patients undergoing complete resection. J Clin Oncol 2015; 33: 3439-3446.

31 Campos-Parra AD, Aviles A, Contreras-Reyes S, et al. Relevance of the novel IASLC/ATS/ERS classification of lung adenocarcinoma in advanced disease. Eur Respir J 2014; 43: 1439-1447.

32 Riely GJ, Travis WD. Can IASLC/ATS/ERS subtype help predict response to chemotherapy in small biopsies of advanced lung adenocarcinoma? Eur Respir J 2014; 43: 1240-1242.

33 Weichert W, Kossakowski C, Harms A, et al. Proposal of a prognostically relevant grading scheme for pulmonary squamous cell carcinoma. Eur Respir J 2016; 47: 938-946.

34 Kadota K, Nitadori J, Woo KM, et al. Comprehensive pathological analyses in lung squamous cell carcinoma: single cell invasion, nuclear diameter, and tumor budding are independent prognostic factors for worse outcomes. J Thorac Oncol 2014; 9: 1126-1139.

35 Moro-Sibilot D, Lantuejoul S, Diab S, et al. Lung carcinomas with a basaloid pattern: a study of 90 cases focusing on their poor prognosis. Eur Respir J 2008; 31: 854-859.

36 Zhao Y, Shen H, Qiu C, et al. Invasion types are associated with poor prognosis in lung squamous carcinoma patients. Medicine 2015; 94: e1634. 